\title{
EDITORIAL
}

\section{The 2019 World Molecular Imaging Congress (WMIC) and Molecular Imaging and Biology (MIB) Awards}

\author{
Jason S. Lewis, ${ }^{1}$ Rosemery Membreno ${ }^{2}$ \\ ${ }^{1}$ Molecular Imaging and Biology \& Memorial Sloan Kettering Cancer Center, New York, NY, USA \\ ${ }^{2}$ Molecular Imaging and Biology \& World Molecular Imaging Society, Culver City, CA, USA
}

In September 2019, the World Molecular Imaging Society (WMIS) held its 12th annual Congress (WMIC) in the beautiful city of Montreal, Canada. The program was masterfully composed by WMIC 2019 Program Co-Chairs Dr. Christin Sander (Martinos Center, Massachusetts General Hospital \& Harvard Medical School, USA) and Dr. Ferdia Gallagher (Cambridge University, UK). Over 1100 scientists from over 35 countries came together to present the latest advances and transformative science in molecular imaging. Highlights of this conference included plenary lectures from top international scientists and the recognition of the work of leading and junior scientists with three top awards: the Gold Medal Award, the Young Investigator Award, and the Roger Tsien Award for Excellence in Chemical Biology. We also had the honor of awarding the inaugural Image of the Year Award for best image featured in a 2018 issue of $M I B$, as well as the best Clinical and Preclinical paper from $M I B$.

The Gold Medal Award was bestowed upon molecular imaging pioneer Katherine W. Ferrara, Ph.D., Professor of Radiology at Stanford University (Fig. 1). Dr. Ferrara's contributions span the field of ultrasound imaging and therapy, including nearly 300 technical papers that have been cited nearly 18,000 times. She pioneered the development and incorporation of ultrasound contrast agents, publishing numerous seminal papers on the physics of the interaction of these agents with ultrasound waves. Her work has had a clinical impact in techniques used worldwide in the diagnosis of cancer. Dr. Ferrara also pioneered imageguided drug delivery, synthesizing new particles and integrating these technologies with imaging methods. Her

Correspondence to: Jason Lewis; e-mail: lewisj2@mskcc.org
Gold Medal Award Lecture, delivered at the closing ceremony of the WMIC, was entitled "Incorporating Ultrasound in Molecular Imaging and Therapy."

A strong emphasis at the annual WMIC is given to highlighting the achievements of young, next-generation scientists making giant breakthroughs in the field of molecular imaging. The winner of the hotly contested Young Investigator Award is determined in various stages throughout the meeting: semifinalists present their work in scientific sessions and three finalists present at the closing ceremony, where the winner is announced and awarded a $\$ 2,000$ cash prize. This year's finalists included Katie Parkins (Western University, Canada) presenting her research on "Engineering Self-Homing Circulating Tumor Cells as Novel Cancer Therapeutics" and Dr. Corrine Beinat (Stanford University) and her work on the "Evaluation of $\left[{ }^{18} \mathrm{~F}\right] \mathrm{DASA}-23$ for noninvasive measurement of aberrantly expressed pyruvate kinase M2 in healthy volunteers and intracranial tumor patients." The winner of the award was Dr. Aisling Chaney from the James Group at Stanford University (Fig. 2), who presented her data in a talk titled "Tracking the Invaders in Multiple Sclerosis: a new highly specific PET imaging approach for visualizing peripheral innate immune activation with higher sensitivity than TSPOPET."

Another early-stage award, The Roger Tsien Award for Excellence in Chemical Biology, is given to an investigator at the level of assistant or associate professor, or equivalent, who has made significant contributions to the field of molecular imaging in the area of chemical biology. Michael Z. Lin, M.D. Ph.D., this year's recipient, presented his lecture on "Breaking brightness barriers: New approaches to improve bioluminescence imaging." Dr. Lin, now an Associate Professor at Stanford University, performed his postdoctoral research in fluorescent protein engineering with Nobel Laureate in Chemistry Dr. Roger Y. Tsien at UCSD. 


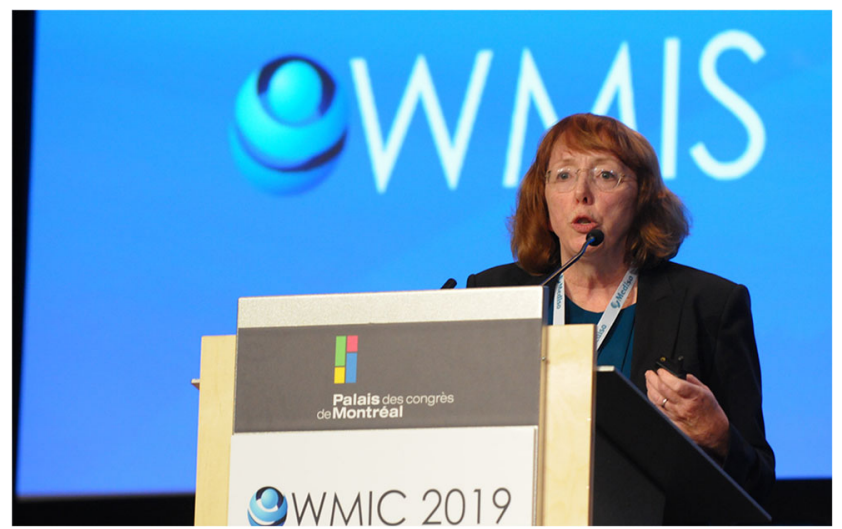

Fig. 1 Professor Katherine W. Ferrara, Ph.D., professor of radiology at Stanford University delivering her Gold Medal Award Lecture.

This journal, Molecular Imaging \& Biology, is the official journal of the WMIS and was well-represented at the meeting. During the closing ceremony of the Congress, the opportunity was taken to present the annual awards for Best Preclinical Paper, Best Clinical Paper, and the Image of the Year (2018). The awards were presented by the Editor-inChief of MIB, Dr. Raymond Gibson. The Best Preclinical Paper was awarded to Beckers et al., "Increased Expression of Translocator Protein (TSPO) Marks Pro-inflammatory Microglia but Does Not Predict Neurodegeneration [1]," the Best Clinical Paper to Georg et al., "Changes in Tumor Biology During Chemoradiation of Cervix Cancer Assessed by Multiparametric MRI and Hypoxia PET [2]," and the Image of the Year was awarded to Ran et al "PET Imaging of Human Brown Adipose Tissue with the TSPO Tracer $\left[{ }^{11} \mathrm{C}\right] \mathrm{PBR} 28$ [3]." The image of the year will also be featured on the cover of one of the 2020 MIB issues.

Additional awards presented at the meeting included the Women in Molecular Imaging Network (WIMIN) Interest Group Leadership Award, given to Dr. Nimmi Ramanujam, Ph.D. of Duke University; Double Helix Optics was the victor at the 2nd Annual Imaging Shark Tank competition, where they were selected by a panel of five "sharks" and walked away with the $\$ 5,000$ grand prize; the 5th annual "This is Our Lab" campaign featured 36 labs who all submitted abstracts to WMIC 2019 - this year's winner was the Robarts Cellular and Molecular Imaging Group (CMIG) at the University of Western Ontario; the Commercial Innovation of the Year Award went to Emile Beaulieu of Photon etc. for their work, "Real Time in vivo Imaging of ICG in the NIR II with the IR VIVOTM Imaging System"; the Poster Award winners were Gedaliah Farber, Emile Gaudin, Travis Shaffer, Babs Sibinga Mulder, Marina Simon, Alejandro Arroyo, Caitlin Tressler, and Do-Wan Lee; the Industry Selected Posters Awards went to Yang Du, Young Hwa Kim, Do-Wan Lee, Dong-Hoon Lee, Nivin Nystrom, Wei Tang, Huaijun Wang, and Xiaochun Xu; the winner of the first annual WMIC Science Elevator-modeled after the very successful and popular postdoc slam/grand slam competitions held at many universities - was Candice Asmore-Harris of King's College London; and finally, the American Chemical Society (ACS)

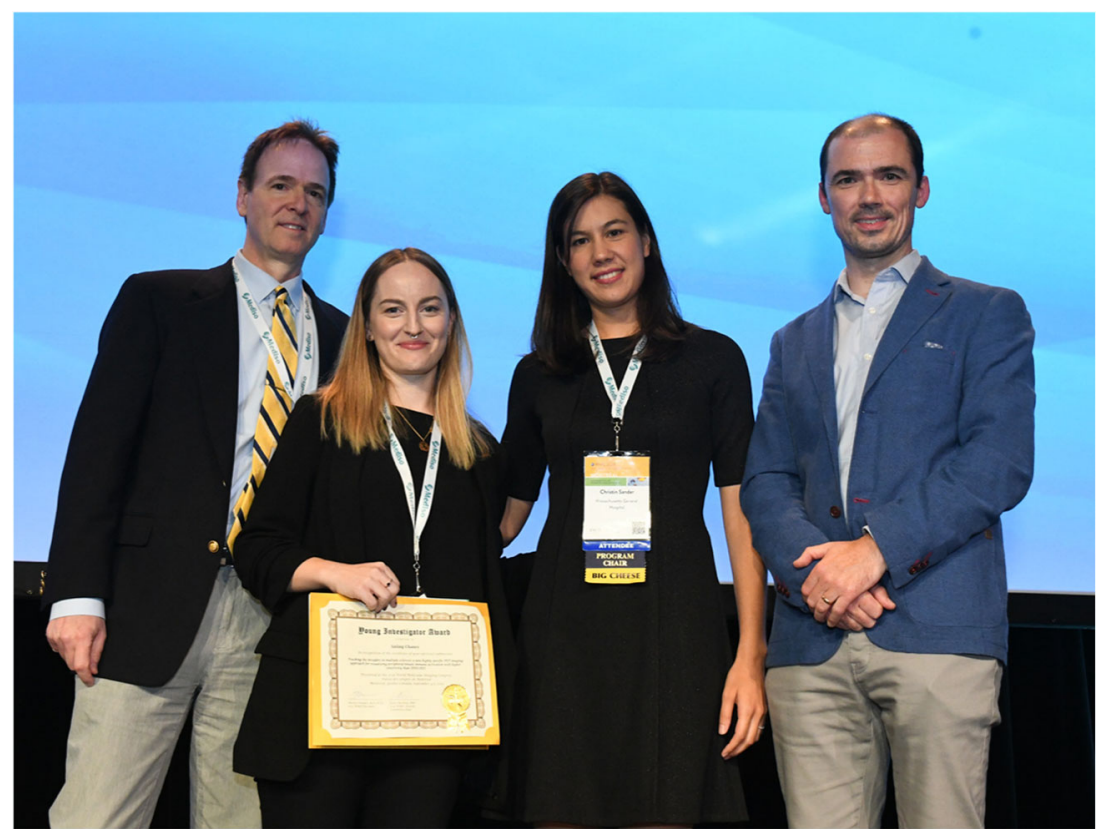

Fig. 2 Dr. Aisling Chaney (second from left) from Stanford University receiving her Young Investigator Award from WMIS President Dr. Martin G. Pomper (left) and WMIC 2019 Program Co-Chairs Drs. Christin Sander (second from right) and Ferdia Gallagher (right). 


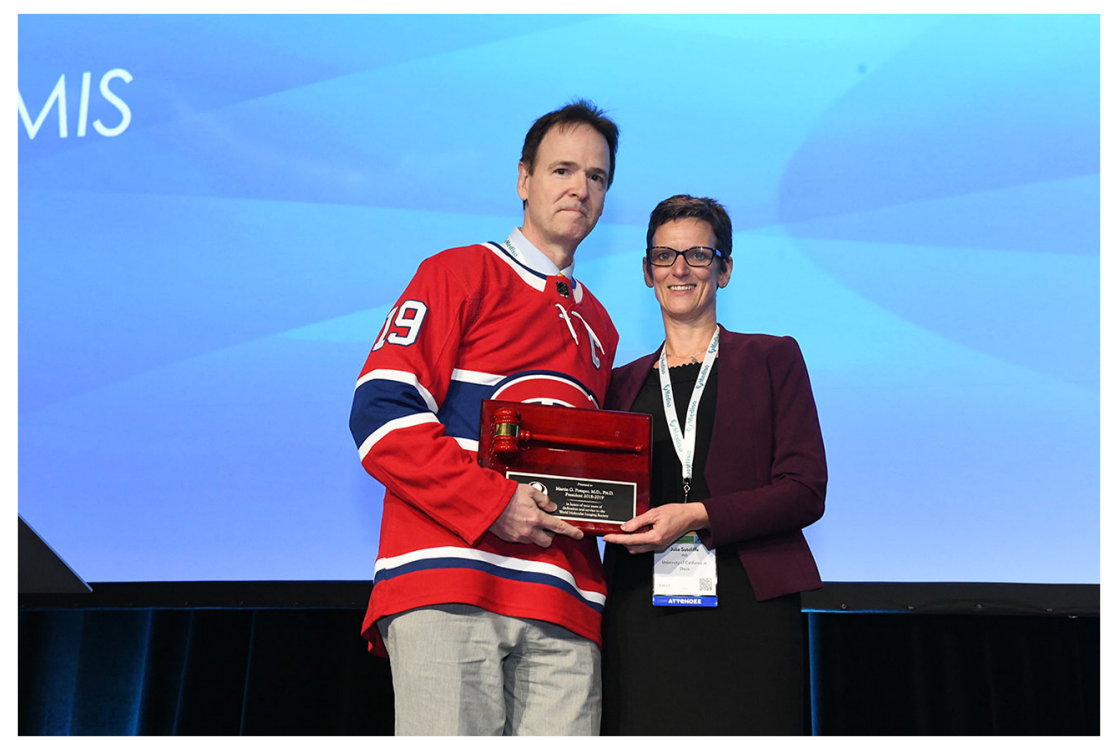

Fig. 3 Presentation of the service plaque to Dr. Martin G. Pomper for his service to the WMIS as president of the society for 2019 by incoming President Julie L. Sutcliffe of UC Davis.

recognized work of high merit in the area of bioconjugate chemistry and presented the 2019 ACS Bioconjugate Chemistry Poster Award to the winners Zhiyang Jin, California Institute of Technology and Yasuhito Maruoka of the NIH/Kyushu University.

Through their service and contributions to molecular imaging and the WMIS, Dr. Carolyn J. Anderson (University of Pittsburgh) and Dr. Jeff W.M. Bulte (Johns Hopkins University) were named Fellows of the World Molecular Imaging Society (FWMIS). The meeting closed with the presentation of a plaque to Dr. Martin G. Pomper, M.D. Ph.D. of Johns Hopkins University for his service to the WMIS as President of the Society for 2019. The plaque was given to him by incoming President Julie L. Sutcliffe, Ph.D. of UC Davis (Fig. 3), who will serve as WMIS President until the 2020 WMIC meeting in Prague, Czech Republic (October 7-10, 2020).

\section{Compliance with Ethical Standards}

\section{Conflict of Interest}

The authors declare that they have no conflict of interest.

\section{References}

1. Beckers L, Geric DOI, Declercq L, Koole M, Kassiou M, Bormans G, Baes M (2018) Increased expression of translocator protein (TSPO) marks pro-inflammatory microglia but does not predict neurodegeneration. Mol Imaging Biol 20:94-102

2. Georg P, Andrzejewski P, Baltzer P, Daniel M, Wadsak W, Mitterhauser M, Sturdza A, Majercakova K, Karanikas G, Pötter R, Hacker M, Helbich T, Georg D, Pinker K (2018) Changes in tumor biology during chemoradiation of cervix cancer assessed by multiparametric MRI and hypoxia PET. Mol Imaging Biol 20:160-169

3. Ran C, Albrecht DS, Bredella MA, Yang J, Yang J, Liang SH, Cypess AM, Loggia ML, Atassi N, Moore A (2018) PET imaging of human brown adipose tissue with the TSPO tracer $\left[{ }^{11} \mathrm{C}\right]$ PBR28. Mol Imaging Biol 20:188-193

Publisher's Note. Springer Nature remains neutral with regard to jurisdictional claims in published maps and institutional affiliations. 